\title{
Removal of $\mathrm{SO}_{2}$ from gas streams using a dielectric barrier discharge and combined plasma photolysis
}

\author{
Moo Been Chang \\ University of Illinois, Department of Civil Engineering, Urbana, Illinois 61801 \\ Jeanne $H$. Balbach \\ University of Illinois, Department of Electrical and Computer Engineering, $1406 \mathrm{~W}$. Green Street, Urbana, \\ Illinois 61801 \\ Mark J. Rood ${ }^{\mathrm{a})}$ \\ University of Illinois, Department of Civil Engineering, Urbana, Illinois 61801 \\ Mark J. Kushnera) \\ University of Illinois, Department of Electrical and Computer Engineering, 1406 W. Green Street, Urbana, \\ Illinois 61801
}

(Received 8 November 1990; accepted for publication 15 January 1991)

\begin{abstract}
The removal of $\mathrm{SO}_{2}$ from simulated gas streams $\left(\mathrm{N}_{2} / \mathrm{O}_{2} / \mathrm{H}_{2} \mathrm{O} / \mathrm{SO}_{2}\right)$ is experimentally investigated using a dielectric barrier discharge, and by computer modeling. Conversion of $\mathrm{SO}_{2}$ to primarily $\mathrm{H}_{2} \mathrm{SO}_{4}$ is found to be limited by the generation of $\mathrm{OH}$ radicals. Increasing the concentrations of $\mathrm{O}_{2}$ and $\mathrm{H}_{2} \mathrm{O}$ increases the generation of $\mathrm{OH}$ radicals and results in more removal of $\mathrm{SO}_{2}$ from gas streams. Removal efficiencies of $>80 \%$ were experimentally achieved. Results from the model suggest that more efficient removal is obtained with a series of short, high $E / N$ current pulses rather than a single, low $E / N$ current pulse. Results from the model also suggest that uv illumination of the plasma to photolyze $\mathrm{O}_{3}$ will improve the removal of $\mathrm{SO}_{2}$ from the gas stream. Photolysis of $\mathrm{O}_{3}$ produces $O\left({ }^{1} D\right)$ atoms which generate $\mathrm{OH}$ radicals by $\mathrm{H}$ abstraction from $\mathrm{H}_{2} \mathrm{O}$, thereby increasing the removal of $\mathrm{SO}_{2}$.
\end{abstract}

\section{INTRODUCTION}

Sulfur dioxide $\left(\mathrm{SO}_{2}\right)$ is a gaseous air contaminant emitted from coal-fired electrical power plants. Its harmful effects have been recorded with respect to human health, vegetation, and materials. ${ }^{1-3}$ Moreover, $\mathrm{SO}_{2}$ emitted into the atmosphere is a precursor to acid rain, being responsible for two-thirds of the acidity of atmospheric precipitation. ${ }^{4}$ Absorption using lime or limestone is the traditional method of removing $\mathrm{SO}_{2}$ from gas streams that are generated by large power plants. The high cost of this technology and the added burden of disposing of large quantities of reaction end products have made absorption techniques less attractive both environmentally and economically. ${ }^{5}$ One alternative to absorption which has been studied for more than a decade is gas-phase oxidation of $\mathrm{SO}_{2}$ using plasmas generated with electron beams (e-beams). ${ }^{6}$ The capital cost and x-ray hazard associated with $e$-beam-based removal systems has motivated studies into alternate plasma-based removal technologies such as pulsed corona discharges, ${ }^{7,8}$ and dielectric barrier discharges (DBD) as demonstrated by Sardja and Dhali. ${ }^{9}$ These discharges use lower voltages $(20-40 \mathrm{kV})$, alternating current, and have lower capital cost compared to e-beams. DBDs are commonly used to generate large volumes of $\mathrm{O}_{3}$ (i.e., ozonizers) ${ }^{10}$ and are now being developed as incoherent uv light sources. ${ }^{11}$ As a result, their technology is beginning to ma- ture and may be transferable to industries requiring the removal of $\mathrm{SO}_{2}$ from gas streams.

Plasma-based removal of $\mathrm{SO}_{2}$ from gases generated by the combustion of fossil fuels containing sulphur relies on two mechanisms. The first, which we call direct removal, is the dissociation of $\mathrm{SO}_{2}$ by direct electron impact or by excitation transfer from other molecules, principally $\mathrm{N}_{2}(\mathrm{~A})$ :

$$
\begin{aligned}
& e+\mathrm{SO}_{2} \rightarrow \mathrm{SO}+\mathrm{O}+e, \\
& \mathrm{~N}_{2}(\mathrm{~A})+\mathrm{SO}_{2} \rightarrow \mathrm{N}_{2}+\mathrm{SO}+\mathrm{O}, \\
& \mathrm{SO}_{2}+\mathrm{O} \rightarrow \mathrm{SO}_{3} .
\end{aligned}
$$

In the absence of other processes, direct removal of $\mathrm{SO}_{2}$ in dry air ultimately results in a conversion of $\mathrm{SO}_{2}$ to other $\mathrm{SO}_{x}$ products ( $\mathrm{SO}, \mathrm{SO}_{3}$ ). The second removal process, which we call chemical removal, is based on chemically altering $\mathrm{SO}_{2}$ to a species that is more easily removed from the gas stream. In moist gas streams, ${ }^{8,12}$ chemical removal is based on the generation of $\mathrm{OH}$ radicals which successively oxidize $\mathrm{SO}_{2}$ to sulfuric acid, $\mathrm{H}_{2} \mathrm{SO}_{4}$,

$$
\begin{aligned}
& \mathrm{OH}+\mathrm{SO}_{2} \rightarrow \mathrm{HSO}_{3}, \quad k_{4 a}=7.4 \times 10^{-12} \mathrm{~cm}^{3} \mathrm{~s}^{-1}, \\
& \mathrm{OH}+\mathrm{HSO}_{3} \rightarrow \mathrm{H}_{2} \mathrm{SO}_{4}, \quad k_{4 b}=9.8 \times 10^{-12} \mathrm{~cm}^{3} \mathrm{~s}^{-1}
\end{aligned}
$$

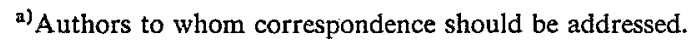


where $k_{i}$ denotes the rate coefficient for the indicated process at a gas temperature of $300 \mathrm{~K}$. Due to the lowequilibrium vapor pressure of $\mathrm{H}_{2} \mathrm{SO}_{4}$, the $\mathrm{H}_{2} \mathrm{SO}_{4}$ molecules will condense from the gas stream resulting in the formation of droplets. These droplets can then be removed by particle separation and removal devices (e.g., fabric filters or electrostatic precipitators).$^{13}$ In the case of flue gases, the object is to make "acid rain" in the flue instead of in the atmosphere. The source of $\mathrm{OH}$ radicals in moist gas is direct electron dissociation impact of $\mathrm{H}_{2} \mathrm{O}$, and dissociative excitation transfer reactions. A particularly efficient source of $\mathrm{OH}$ is the hydrogen abstraction reaction from $\mathrm{H}_{2} \mathrm{O}$ by $O\left({ }^{1} D\right)$ atoms, ${ }^{14}$

$$
e+\mathrm{O}_{2} \rightarrow \mathrm{O}+\mathrm{O}\left({ }^{1} D\right) \stackrel{\mathrm{H}_{2} \mathrm{O}}{\rightarrow} \mathrm{OH}+\mathrm{OH} .
$$

In e-beam-generated plasmas, $\mathrm{OH}$ radicals are produced dominantly through an ion channel. ${ }^{12}$ One such initiating reaction is charge exchange from $\mathrm{N}_{2}^{+}$,

$$
e_{\text {beam }}+\mathrm{N}_{2} \rightarrow \mathrm{N}_{2}^{+} \stackrel{\mathrm{H}_{2} \mathrm{O}}{\rightarrow} \mathrm{H}_{2} \mathrm{O}^{+} \stackrel{\mathrm{H}_{2} \mathrm{O}}{\rightarrow} \mathrm{H}_{3} \mathrm{O}^{+}+\mathrm{OH} \text {. }
$$

Here the production of a single $\mathrm{OH}$ radical requires at least $15.5 \mathrm{eV}$ (ionization potential of $\mathrm{N}_{2}$ ). In electric discharge devices such as DBDs, $\mathrm{OH}$ is dominantly produced through the neutral channel as shown in Eq. (5).

In this paper, we report on an experimental and theoretical study of the removal of $\mathrm{SO}_{2}$ from gas streams using a DBD. We experimentally obtained $>80 \%$ removal of $\mathrm{SO}_{2}$ in a simulated gas stream having an initial $\mathrm{SO}_{2}$ concentration $\left(\left[\mathrm{SO}_{2}\right]\right)$ of 1000 ppmv (parts per million by volume) in a gas mixture of $\mathrm{N}_{2} / \mathrm{O}_{2} / \mathrm{H}_{2} \mathrm{O}=76.9 / 20.5 / 2.6$. The removal efficiency of $\mathrm{SO}_{2}$ increased with increasing $\left[\mathrm{H}_{2} \mathrm{O}\right]$ and $\left[\mathrm{O}_{2}\right]$ in the gas stream indicating that chemical removal is a more efficient removal mechanism than direct removal. These observations are consistent with suggestions resulting from previous studies of corona and $e$-beam irradiation. ${ }^{8,12}$ Based on these results and those from a computer model for plasmabased removal of $\mathrm{SO}_{2}$, we propose that a system using combined plasma excitation and photolysis of chemical reaction products will result in more efficient removal of $\mathrm{SO}_{2}$ than chemical removal using a DBD only.

In Sec. II, the experimental apparatus and procedures will be described. The computer model for plasma processing of $\mathrm{SO}_{2}$ and important reaction pathways will be discussed in Sec. III. Experimental and modeling results for $\mathrm{SO}_{2}$ removal will be presented in Sec. IV, followed by our proposal for a more efficient method of removing $\mathrm{SO}_{2}$ by combining plasma with optical processing in Sec. V. Our concluding remarks are in Sec. VI.

\section{DESCRIPTION OF THE EXPERIMENTAL APPARATUS}

The experimental apparatus used in this study is shown in Fig. 1. The streams simulating fue gases were generated using compressed gases $\left(\mathrm{SO}_{2}, \mathrm{~N}_{2}\right.$, and drygrade air) regulated by mass flow controllers (Tylan, Inc., Model No. FC-260 and FC-280). ${ }^{15} \mathrm{H}_{2} \mathrm{O}$ was added to the gas by passing part of the stream through a controlled temperature $\mathrm{H}_{2} \mathrm{O}$ bath. $\left[\mathrm{H}_{2} \mathrm{O}\right]$ was determined with a dew point hygrometer (General Eastern Hygro-M1). The range of $\left[\mathrm{H}_{2} \mathrm{O}\right]$ was $0 \%-2.6 \%$ by volume. The discharge vessel was made of uv grade quartz having an outer diameter of $4 \mathrm{~cm}$ and a wall thickness of $0.2 \mathrm{~cm}$. The coaxial electrodes that generated the DBDs were a $0.24-\mathrm{cm}$-diam tungsten rod located along the center line of the reactor and a stainless stccl wirc mcsh wrappcd around the outside of the reactor. The plasma volume was $\approx 250 \mathrm{~cm}^{3}$. The power supply was a variable voltage transformer that provided up to $30 \mathrm{kV}$ (peak value) at $60 \mathrm{~Hz}$. Discharges occurred on the anodic and cathodic cycles, yielding an effective repetition rate of $120 \mathrm{~Hz}$. Discharges occurred with voltage settings $\geqslant 21 \mathrm{kV}$ (peak value). The $\left[\mathrm{SO}_{2}\right]$ was measured with a fluorescence detector (Monitor Laboratory Model $8850 \mathrm{HL}$ ) after diluting with $\mathrm{N}_{2}$ (Monitor Laboratory Model 8730). All experiments were performed at 1 atm and $\approx 295 \mathrm{~K}$. The inlet $\left[\mathrm{SO}_{2}\right]\left(\left[\mathrm{SO}_{2}\right]_{0}\right)$ ranged from 300-1000 ppmv. The percent of $\mathrm{SO}_{2}$ removed from the gas stream $\eta$ was determined by

$$
\eta(\%)=\frac{\left(\left[\mathrm{SO}_{2 \text { (off) }}\right]-\left[\mathrm{SO}_{2(\text { on })}\right]\right)}{\left[\mathrm{SO}_{2(\text { off })}\right]} 100,
$$

where the subscripts denote flowing operation of the cell with the DBD on and off, respectively.

\section{DESCRIPTION OF THE MODEL AND REACTION PATHWAYS}

A comprehensive computer model has been developed to simulate plasma excitation and processing of gas streams produced by sulfur-containing fuel combustors. The model is conceptually similar to other models of atmospheric pressure discharges, such as those used for avalaniche lasers ${ }^{16}$ and therefore will be only briefly described. The simulation consists of submodels for the discharge circuitry, electron kinetics, and heavy particle plasma chemistry. Electron impact rate coefficients are obtained by solving Boltzmann's equation for the electron energy distribution using a two-term spherical harmonic expansion. ${ }^{17}$ We are able to simulate plasma excitation of gas streams initially consisting of mixtures of $\mathrm{N}_{2}, \mathrm{O}_{2}, \mathrm{H}_{2} \mathrm{O}, \mathrm{CO}_{2}, \mathrm{SO}_{2}, \mathrm{NO}$, and $\mathrm{NO}_{2}$. The $120-\mathrm{Hz}$ plasma excitation used in the experiment is modeled by simulating successive discharge pulses and their afterglows. The initial conditions (species mole fractions) for a given discharge pulse are obtained from the values at the end of the previous afterglow.

To account for the pertinent plasma chemistry during and following the discharge, a total of 74 species and 360 reactions are included in the model. The choice of reaction mechanisms were guided by previous models of $\mathrm{SO}_{2}$ removal in e-beam-excited plasmas. ${ }^{18-20}$ The dominant reaction pathways are shown in Fig. 2. $\mathrm{SO}_{2}$ may be directly dissuciated, dominantly to $\mathrm{SO}+\mathrm{O}$, by electron impact or excitation transfer. Dissociation by excitation transfer proceeds primarily by collisions with electronically excited $\mathrm{N}_{2}\left(k_{2}=3 \times 10^{-11} \mathrm{~cm}^{3} \mathrm{~s}^{-1}\right) .{ }^{18} \mathrm{~N}_{2}$ has the highest mole 


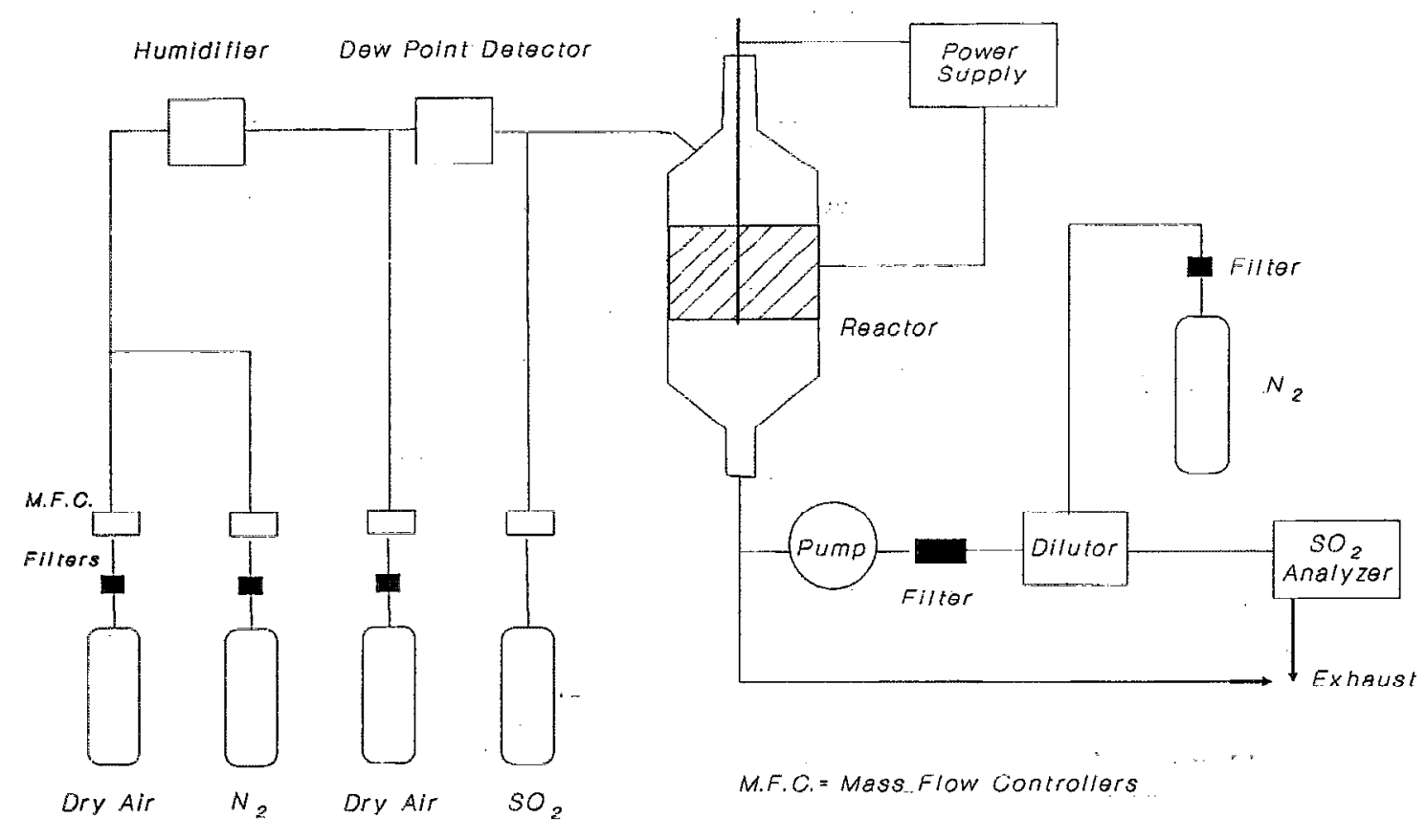

FIG. 1. Schematic of gas generator, dielectric barrier discharge reactor cell, and gas detection system.

fraction in the gas stream and absorbs the majority of the deposited energy. Excitation transfer therefore is a dominant method of dissociating $\mathrm{SO}_{2}$. Reactions of $\mathrm{SO}$ with $\mathrm{O}$, $\mathrm{O}_{2}, \mathrm{OH}$, and $\mathrm{O}_{3}$ reform $\mathrm{SO}_{2}$, with the first three reactions contributing approximately equally, and the latter contributing to a lesser degree. $\mathrm{SO}_{2}$ is removed by reactions with $\mathrm{OH}$, [Eq. (4a)] forming $\mathrm{HSO}_{3}$, while reactions with $\mathrm{O}$ and $\mathrm{H}_{2} \mathrm{O}$ remove $\mathrm{SO}_{2}$ by forming $\mathrm{SO}_{3}$. Only the reaction with $\mathrm{O}$ $\left(k=3.4 \times 10^{-14} \mathrm{~cm}^{3} \mathrm{~s}^{-1}\right)$ contributes significantly to the formation of $\mathrm{SO}_{3}$, which may itself be hydrolyzed by $\mathrm{H}_{2} \mathrm{O}$ to form $\mathrm{H}_{2} \mathrm{SO}_{4}\left(k=8.5 \times 10^{-13} \mathrm{~cm}^{3} \mathrm{~s}^{-1}\right)$. The oxidation chain of $\mathrm{SO}_{2}+2 \cdot \mathrm{OH} \rightarrow \mathrm{H}_{2} \mathrm{SO}_{4}$ [Eqs. (4a) and (b)] may be broken by interception of $\mathrm{HSO}_{3}$ by $\mathrm{O}_{2}$ to form $\mathrm{SO}_{3}$ and $\mathrm{HO}_{2}\left(\mathrm{k}=4 \times 10^{-13} \mathrm{~cm}^{3} \mathrm{~s}^{-1}\right)$. Due to the large $\left[\mathrm{O}_{2}\right]$, this reaction proceeds quickly. This condition indicates that a critical value of $\left[\mathrm{H}_{2} \mathrm{O}\right]$ in the gas stream is necessary to ensure oxidation of $\mathrm{SO}_{3}$ to $\mathrm{H}_{2} \mathrm{SO}_{4}$.

The formation of $\mathrm{OH}$ is dominated by two processes in electric discharges: direct electron impact and hydrogen abstraction from $\mathrm{H}_{2} \mathrm{O}$,

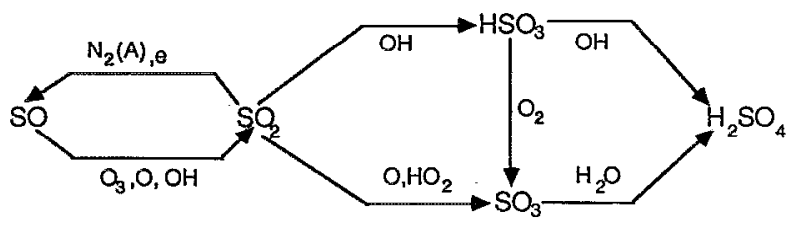

FIG. 2. Schematic of the dominant direct and chemical reaction pathways to remove $\mathrm{SO}_{2}$ from gas streams. Direct removal results primarily in producing other $\mathrm{SO}_{x}$ species. Chemical removal is optimized by generation of $\mathrm{OH}$ radicals.

$$
\begin{aligned}
& e+\mathrm{H}_{2} \mathrm{O} \rightarrow \mathrm{OH}+\mathrm{H}+e, \quad k_{8}=6.8 \times 10^{-12} \mathrm{~cm}^{3} \mathrm{~s}^{-1} \\
& e+\mathrm{O}_{2} \rightarrow \mathrm{O}\left({ }^{1} D\right)+\mathrm{O}+e, \quad k_{9}=4.8 \times 10^{-9} \mathrm{~cm}^{3} \mathrm{~s}^{-1}, \\
& \mathrm{O}\left({ }^{1} D\right)+\mathrm{H}_{2} \mathrm{O} \rightarrow \mathrm{OH}+\mathrm{OH}, \quad k_{10}=2.2 \times 10^{-10} \mathrm{~cm}^{3} \mathrm{~s}^{-1},
\end{aligned}
$$

where rate coefficients for electron impact processes are shown for typical midpulse conditions. Smaller amounts of $\mathrm{OH}$ are contributed through charge-exchange reactions, as shown in Eq. (6). Due to the much larger reaction rate constant in Eq. (9) (while $\left[\mathrm{O}_{2}\right]$ and $\left[\mathrm{H}_{2} \mathrm{O}\right]$ are of the same order of magnitude), the production of $\mathrm{OH}$ is dominated by hydrogen abstraction from $\mathrm{H}_{2} \mathrm{O}$ by $\mathrm{O}\left({ }^{1} D\right)$ under most conditions. Reactions that deplete $O\left({ }^{1} D\right)$ will reduce the rate of removal of $\mathrm{SO}_{2}$ due to the accompanying reduction in the production of $\mathrm{OH}$. These reactions are primarily

$$
\begin{gathered}
\mathrm{O}\left({ }^{1} D\right)+\mathrm{N}_{2} \rightarrow \mathrm{O}+\mathrm{N}_{2}, \quad k_{11}=2.6 \times 10^{-11} \mathrm{~cm}^{3} \mathrm{~s}^{-1}, \\
\mathrm{O}\left({ }^{1} D\right)+\mathrm{O}_{2} \rightarrow \mathrm{O}+\mathrm{O}_{2}, \quad k_{12}=3.8 \times 10^{-11} \mathrm{~cm}^{3} \mathrm{~s}^{-1}, \\
\mathrm{O}\left({ }^{1} D\right)+\mathrm{H}_{2} \mathrm{O} \rightarrow \mathrm{O}+\mathrm{H}_{2} \mathrm{O}, \quad k_{13}=1.2 \times 10^{-11} \mathrm{~cm}^{3} \mathrm{~s}^{-1}
\end{gathered}
$$

The combined $\left[\mathrm{O}_{2}\right]$ and $\left[\mathrm{N}_{2}\right]$ are always large compared to that for the $\left[\mathrm{H}_{2} \mathrm{O}\right]$. Therefore quenching of $\mathrm{O}\left({ }^{1} D\right)$ is a significant loss mechanism for the production of $\mathrm{OH}$. However, since the rate coefficient for hydrogen abstraction from $\mathrm{H}_{2} \mathrm{O}$ producing $\mathrm{OH}$ is large compared to that for quenching, smaller amounts of $\mathrm{H}_{2} \mathrm{O}$ can beneficially con- 


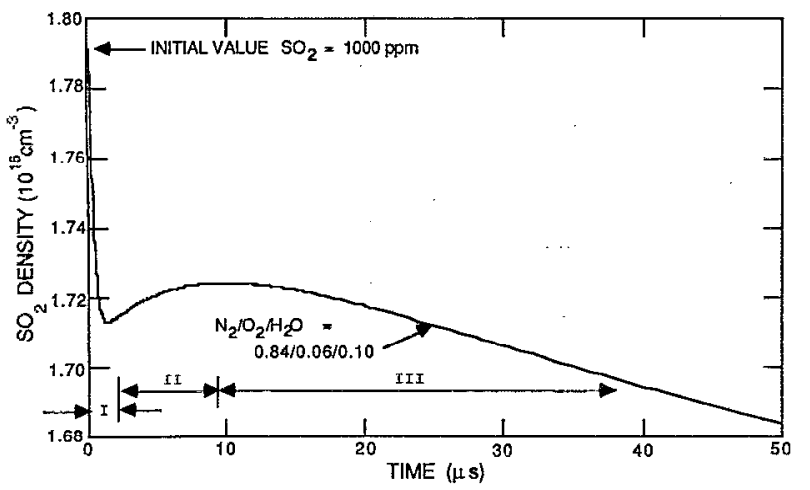

FIG. 3. $\mathrm{SO}_{2}$ concentration following a current pulse showing three reaction regimes. I: direct removal; II: reformation, and III: chemical removal.

sume the majority of the $O\left({ }^{1} D\right)$ produced. The mole fraction of $\mathrm{H}_{2} \mathrm{O}\left[\int\left(\mathrm{H}_{2} \mathrm{O}\right)\right]$ required to dominate $\mathrm{O}\left({ }^{1} D\right)$ usage is approximately

$f\left(\mathrm{H}_{2} \mathrm{O}\right)>\left[f\left(\mathrm{~N}_{2}\right) k_{11}+f\left(\mathrm{O}_{2}\right) k_{12}\right] /\left(k_{10}-k_{13}\right)=0.16$.

Large improvements in the removal of $\mathrm{SO}_{2}$ are therefore expected when increasing $\left[\mathrm{O}_{2}\right]$ and $\left[\mathrm{H}_{2} \mathrm{O}\right]$ to approximately $10 \%$ to $20 \%$ by volume.

During a single discharge pulse and its afterglow, the $\left[\mathrm{SO}_{2}\right]$ is determined by a combination of the reactions described above. The conditions at which these processes dominate, however, are different. For example, the $\left[\mathrm{SO}_{2}\right]$ during and immediately after a single discharge (pulse length $=500 \mathrm{~ns}$ ) in a $\mathrm{N}_{2} / \mathrm{O}_{2} / \mathrm{H}_{2} \mathrm{O}=0.84 / 0.06 / 0.10 \mathrm{mix}$ ture having an initial $\left[\mathrm{SO}_{2}\right]=1000 \mathrm{ppmv}$ is shown in Fig. 3. During the period labeled $\mathrm{I}, \mathrm{SO}_{2}$ is removed by dissociation to SO dominantly by electron impact and excitation transfer from $\mathrm{N}_{2}(\mathrm{~A})$. During the first few $\mu \mathrm{s}$ following the discharge pulse (labeled II), SO reforms to $\mathrm{SO}_{2}$ by collisions with $\mathrm{O}$ thereby replenishing its concentration. In the following tens of $\mu \mathrm{s}, \mathrm{SO}_{2}$ is oxidized by $\mathrm{OH}$ to $\mathrm{H}_{2} \mathrm{SO}_{4}$ and is therefore permanently removed from the gas phase.

\section{REMOVAL OF $\mathrm{SO}_{2}$ USING A DIELECTRIC BARRIER DISCHARGE}

\section{A. Experimental results}

Due to the filamentary nature of the DBD, the entire gas volume is not excited every discharge pulse. The typical area density of microstreamers in a DBD is a few per $\mathrm{cm}^{2}$, and their diameters are many hundreds of micrometers. ${ }^{21}$ For a discharge frequency of $120 \mathrm{~Hz}$ and gas residence time of a few seconds, the average volume of gas is processed by approximately $2-10$ pulses. The removal of $\mathrm{SO}_{2}$ we measure at gas residence times of a few seconds therefore results from at most tens of discharge pulses per unil volume of the gas.

The dependence of removal efficiency $\eta$ on residence time of the gas in the reactor and applied voltage is shown in Fig. 4. The gas mixture is $\mathrm{N}_{2} / \mathrm{O}_{2} / \mathrm{H}_{2} \mathrm{O}=76.9 /$

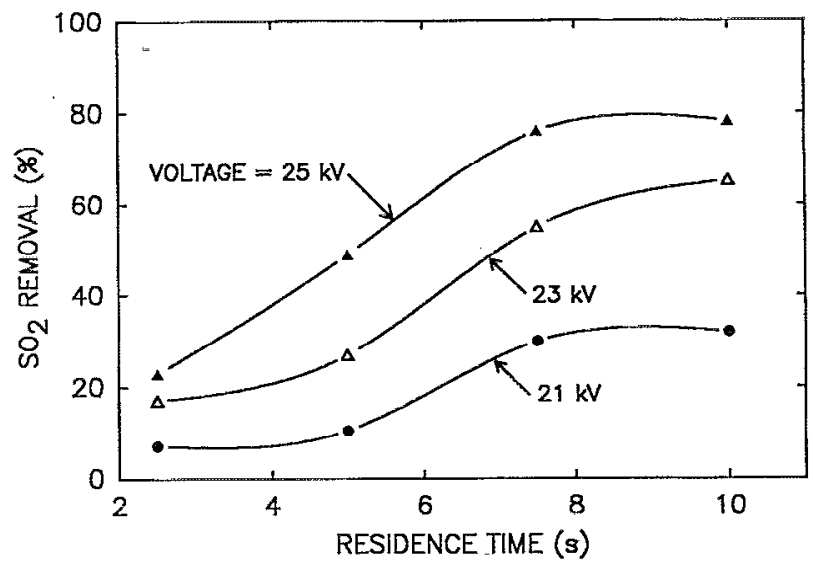

FIG. 4. Percent removal of $\mathrm{SO}_{2}$ (initial concentration $1000 \mathrm{ppmv}$ ) from a $\mathrm{N}_{2} / \mathrm{O}_{2} / \mathrm{H}_{2} \mathrm{O}=76.9 / 20.5 / 2.6$ mixture as a function of gas residence time in the reactor. Results are shown for different excitation voltages. These results imply that removal does not depend solely on energy deposition.

$20.5 / 2.6$ with an $\left[\mathrm{SO}_{2}\right]_{0}$ of 1000 ppmv. $\eta$ increases with increasing gas residence time, and corresponding energy deposition, up to $7 \mathrm{~s}$ and then levels off between 7.5 and 10 s. In excess of $80 \%$ removal is obtained for these conditions. For the same gas residence time, increasing voltage, and hence energy deposition, increases $\eta$ even when removal is saturated due to gas residence time. These results suggest that $\eta$ does not necessarily simply scale with energy deposition but also depends on the manner of energy deposition. The current pulse width in DBDs scales inversely with ionization rate which increases with increasing voltage. ${ }^{21}$ These observations imply that for a given total energy deposition, $\eta$ increases with decreasing current pulse width. This trend is also suggested by results from the model, as will be discussed below.

The removal of $\mathrm{SO}_{2}$ as a function of $\left[\mathrm{SO}_{2}\right]_{0}$ is shown in Fig. 5 for different processing voltages. The carrier gas mixture is $\mathrm{N}_{2} / \mathrm{O}_{2} / \mathrm{H}_{2} \mathrm{O}=76.9 / 20.5 / 2.6$ and the gas residence time is $5 \mathrm{~s}$. Both the percent and absolute removal of $\mathrm{SO}_{2}$ are shown. In excess of $80 \%$ removal is obtained for $\left[\mathrm{SO}_{2}\right]_{0}=300$ ppmv. $\mathrm{SO}_{2}$ removal increases with increasing voltage and energy deposition; however, the fractional removal monotonically decreases with increasing $\left[\mathrm{SO}_{2}\right]_{0}$. The absolute removal, though, behaves differently. At lower energy deposition the absolute removal is constant with increasing $\left[\mathrm{SO}_{2}\right]_{0}$, implying that the removal is limited by energy deposition. At higher-energy deposition, the absolute removal increases with increasing $\left[\mathrm{SO}_{2}\right]_{0}$ for values $\lesssim 600$ ppmv implying that the process is not energy limited for those concentrations. At low $\left[\mathrm{SO}_{2}\right]_{0}$, the majority of removal occurs early during the current pulse and afterglow. Additional precursors to the removal of $\mathrm{SO}_{2}$ are otherwise consumed before reacting with $\mathrm{SO}_{2}$ or $\mathrm{HSO}_{3}$ because of the low concentrations of these species. Increasing $\left[\mathrm{SO}_{2}\right]$ increases the probability that these precursors are beneficially utilized. For example, a competing process for the consumption of $\mathrm{OH}$ is 


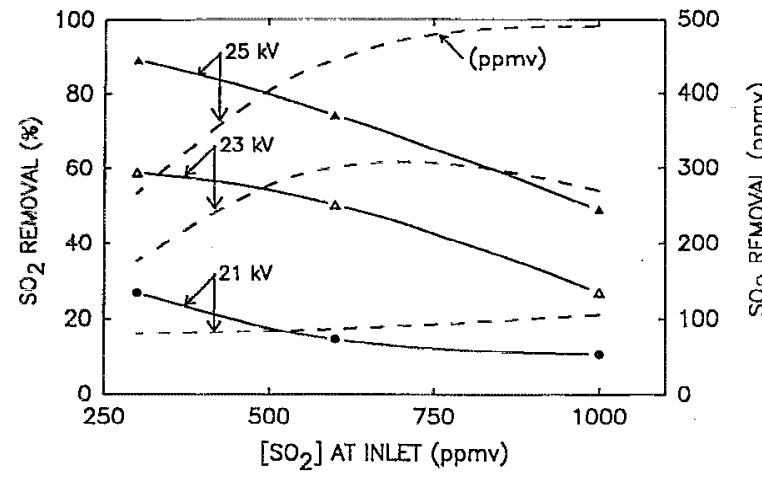

FIG. 5. Percent and absolute removal of $\mathrm{SO}_{2}$ as a function of $\left[\mathrm{SO}_{2}\right]$ at the inlet of the reactor for various operating voltages $\left(\mathrm{N}_{2} / \mathrm{O}_{2} / \mathrm{H}_{2} \mathrm{O}=76.9 / 20.5 / 2.6\right.$, gas residence time $\left.=5 \mathrm{~s}\right)$. Although percent removal decreases with increasing inlet $\left[\mathrm{SO}_{2}\right]$, in most cases the absolute removal increases. This implies a more efficient utilization of precursors to removal of $\mathrm{SO}_{2}$ from the gas stream.

$$
\mathrm{OH}+\mathrm{O} \rightarrow \mathrm{O}_{2}+\mathrm{H}, \quad k_{15}=3.0 \times 10^{-11} \mathrm{~cm}^{3} \mathrm{~s}^{-1} .
$$

To ensure efficient utilization of $\mathrm{OH}$, one must have $\left[\mathrm{SO}_{2}\right] /[\mathrm{O}]>k_{15} / k_{4 a} \approx 0.5$. During processing, the maximum [O] is $1-10 \times 10^{15} \mathrm{~cm}^{-3}$ which corresponds to 40 400 ppmv. Therefore, in order to efficiently utilize $\mathrm{OH}$, $\left[\mathrm{SO}_{2}\right]_{0}$ must exceed many hundred ppmv, which is confirmed by the results in Fig. 5 .

The dependence of the removal efficiency of $\mathrm{SO}_{2}$ on $\left[\mathrm{H}_{2} \mathrm{O}\right]_{0}$ is shown in Fig. 6 . The $\left[\mathrm{O}_{2}\right]$ is $20.5 \%$ by volume, the gas residence time is $5 \mathrm{~s}$, and $\left[\mathrm{SO}_{2}\right]_{0}=1000 \mathrm{ppmv}$. $\eta$ is negligible in the absence of $\mathrm{H}_{2} \mathrm{O}$, but increases with increasing $\left[\mathrm{H}_{2} \mathrm{O}\right]_{0}$ to the maximum value used, $2.6 \%$ by volume. The improvement in removal efficiency with increasing $\left[\mathrm{H}_{2} \mathrm{O}\right]_{0}$ results from an increasing chemical component to the removal, a consequence of production of increasing concentrations of $\mathrm{OH}$ radicals. ${ }^{8,12}$ The direct removal of $\mathrm{SO}_{2}$ dominantly converts $\mathrm{SO}_{2}$ to $\mathrm{SO}_{3}$. The low removal of $\mathrm{SO}_{2}$ in the absence of $\mathrm{H}_{2} \mathrm{O}$ implies that there is an efficient rate of chemically reducing $\mathrm{SO}_{3}$ thereby reforming $\mathrm{SO}_{2}$, when $\mathrm{SO}_{3}$ is not hydrolyzed by $\mathrm{H}_{2} \mathrm{O}$.

The dependence of $\eta$ on $\left[\mathrm{O}_{2}\right]_{0}$ is shown in Fig. 7 for an $\left[\mathrm{H}_{2} \mathrm{O}\right]$ of $1.8 \%$ by volume. $\eta$ increases sharply with increasing $\left[\mathrm{O}_{2}\right]_{0}$ up to $5 \%$ by volume with a more gradual increase for $\left[\mathrm{O}_{2}\right]_{0}$ of $5 \%-21 \%$ by volume. The low rate of removal at small $\left[\mathrm{O}_{2}\right]$ is indicative of the low efficiency of the direct removal mechanism for these conditions. The production of $\mathrm{OH}$ radicals is low in the absence of $\mathrm{O}_{2}$ since $\mathrm{OH}$ is then produced primarily by direct electron impact of $\mathrm{H}_{2} \mathrm{O}$ or excitation transfer from $\mathrm{N}_{2}(A)$. Therefore the direct removal mechanism dominates, which ultimately depends on hydrolysis of $\mathrm{SO}_{3}$ by $\mathrm{H}_{2} \mathrm{O}$ for permanent removal. As $\left[\mathrm{O}_{2}\right]_{0}$ increases, the rate of production of $\mathrm{OH}$ also increases, principally by production of $\mathrm{O}\left({ }^{1} D\right)$ atoms and abstraction reactions as shown in Eq. (5). The saturation of the removal of $\mathrm{SO}_{2}$ with increasing $\left[\mathrm{O}_{2}\right]$ is largely due to insufficient $\left[\mathrm{H}_{2} \mathrm{O}\right]$. That is, the rate of production of $\mathrm{OH}$ is not limited by the production of precursors such as $\mathrm{O}\left({ }^{1} D\right)$ but rather by the lack of $\mathrm{H}_{2} \mathrm{O}$. Under these condi-

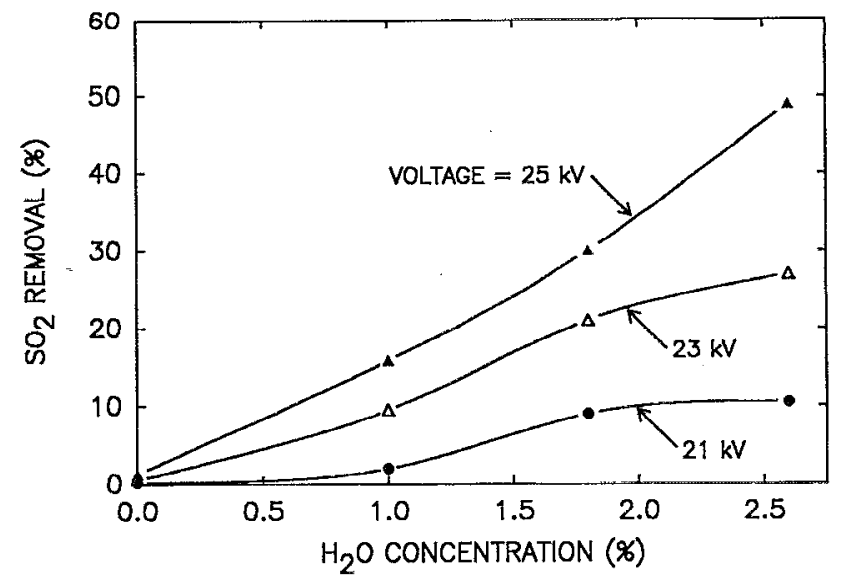

FIG. 6. Percent $\mathrm{SO}_{2}$ removal as a function of $\left[\mathrm{H}_{2} \mathrm{O}\right]_{0}$ for various applied voltages $\left(\mathrm{N}_{2} / \mathrm{O}_{2}=76.9 / 20.5,\left[\mathrm{SO}_{2}\right]_{0}=1000 \mathrm{ppmv}\right)$. In all cases, removal increases with increasing water content, indicating an increasing rate of generation of $\mathrm{OH}$ radicals.

tions, $O\left({ }^{1} D\right)$ decays by collisional deactivation with $\mathrm{O}_{2}$ and $\mathrm{N}_{2}$, as shown in Eqs. (11) and (12). In general, the optimum $\left[\mathrm{H}_{2} \mathrm{O}\right]$ increases with increasing $\left[\mathrm{O}_{2}\right]$. The calculated optimum value of $\left[\mathrm{H}_{2} \mathrm{O}\right]$ at $\left[\mathrm{O}_{2}\right]=20 \%$ is approximately $10 \%-15 \%$. This range of values for $\left[\mathrm{H}_{2} \mathrm{O}\right]$ is typically obtained in gases produced by the combustion of coal.

\section{B. Model results}

The entire gas volume is not processed on every discharge pulse in a DBD, as discussed above. To reduce the length of the calculation when stimulating the experiments, though, we assumed that the entire gas volume was processed each half-cycle by individual pulses somewhat longer than those commonly associated with DBDs (many hundreds as opposed to tens of nanoseconds). In this way, only 4-10 individual discharge pulses and afterglows need

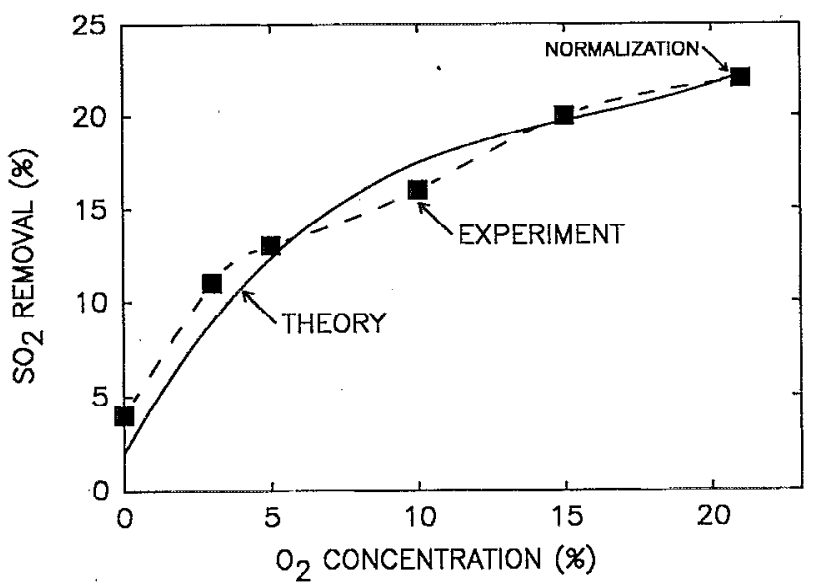

FIG. 7. Percent removal of $\mathrm{SO}_{2}$ as a function of $\left[\mathrm{O}_{2}\right]_{0}\left(\left[\mathrm{H}_{2} \mathrm{O}\right]_{0}\right.$ $=0.018)$. Experimental and theoretical results are shown, normalized at $\left[\mathrm{O}_{2}\right]_{0}=0.22$. $\mathrm{SO}_{2}$ removal increases with increasing concentration of $\mathrm{O}_{2}$ due to more efficient production of $\mathrm{OH}$ radicals, until production is limited by the lack of $\mathrm{H}_{2} \mathrm{O}$. 


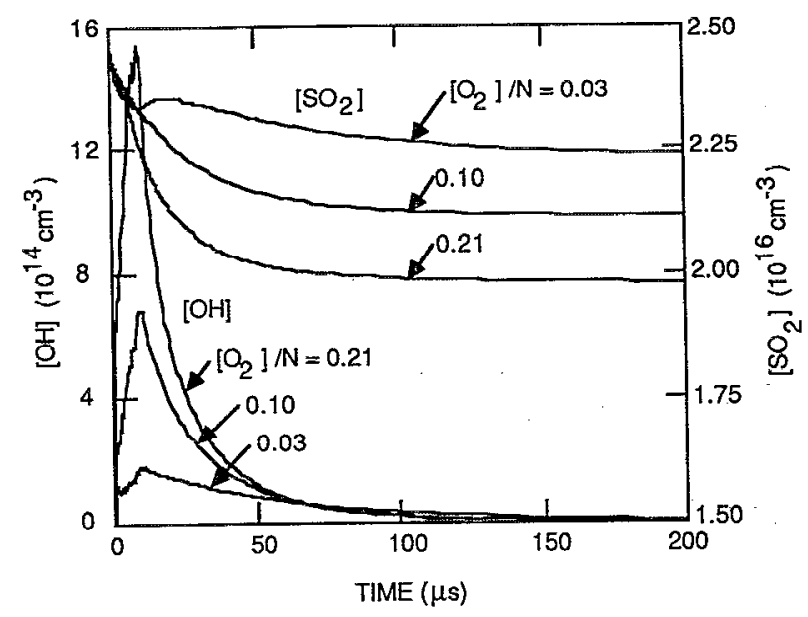

FIG. 8. Simulated $\left[\mathrm{SO}_{2}\right]$ and $[\mathrm{OH}]$ immediately after a current pulse (duration $<1 \mu \mathrm{s}$ ) for different $\left[\mathrm{O}_{2}\right]_{0}$. Production of $\mathrm{OH}$ increases with increasing $\left[\mathrm{O}_{2}\right]_{0}$, and is maximum after the current pulse. Chemical removal of $\mathrm{SO}_{2}$ continues for many ins after the current pulse.

to be calculated for a given set of conditions. In order for this assumption to be valid, the products of any plasmainitiated chemistry must reach a new equilibrium composition during the $8.3-\mathrm{ms}$ between pulses. As shown below, this is the case.

The computed removal of $\mathrm{SO}_{2}$ for various $\left[\mathrm{O}_{2}\right]_{0}$ is shown as the solid line in Fig. 7. Because of uncertainties in the energy deposition in the reactor, the calculation was normalized to the experiment at $\left[\mathrm{O}_{2}\right]_{0}=21 \%$ by varying the total-energy deposition in the model. Following this method for normalization, agreement at $\left[\mathrm{O}_{2}\right]_{0}=21 \%$ was obtained with an energy deposition of $30 \mathrm{~mJ} \mathrm{~cm}^{-3}$. For an average gas residence time of $5 \mathrm{~s}$, this is a power deposition of $6 \mathrm{~mW} \mathrm{~cm}{ }^{-3}$. The agreement with experiment at other values of $\left[\mathrm{O}_{2}\right]_{0}$ is quite good. The $[\mathrm{OH}]$ and $\left[\mathrm{SO}_{2}\right]$ during and after a single current pulse are shown in Fig. 8 for different $\left[\mathrm{O}_{2}\right]_{0}$. Increasing $\left[\mathrm{O}_{2}\right]_{0}$ results in a higher rate of generation of $\mathrm{OH}$ which contributes directly to the removal of $\mathrm{SO}_{2}$. These results confirm that at low $\left[\mathrm{O}_{2}\right]$, removal of $\mathrm{SO}_{2}$ is limited hy lack of generation of $\mathrm{OH}$ due to insufficient production of $\mathrm{O}\left({ }^{1} D\right)$. At high $\left[\mathrm{O}_{2}\right], \mathrm{OH}$ production, and hence $\mathrm{SO}_{2}$ removal, is limited by the lack of $\mathrm{H}_{2} \mathrm{O}$. That is, $\mathrm{O}\left({ }^{1} D\right)$ reacts with other species prior to reacting with $\mathrm{H}_{2} \mathrm{O}$.

The $\left[\mathrm{SO}_{2}\right]$ during and after a series of discharge pulses $(120 \mathrm{~Hz})$ is shown in Fig. 9. For these results, the initial gas temperature was $410 \mathrm{~K}$, reflecting conditions more similar to those for gases generated by combustion. Concentrations are shown for two total-energy depositions 60 and $100 \mathrm{~mJ} \mathrm{~cm}=3$. The energy is deposited in either a single pulse or in four smaller pulses. During any single discharge pulse, only $10 \%-15 \%$ of the initial $\mathrm{SO}_{2}$ is removed; a substantial amount of removal of $\mathrm{SO}_{2}$ is obtained by a series of such pulses in a DBD. The removal of $\mathrm{SO}_{2}$ per pulse logically increases with increasing energy deposition. The total removal of $\mathrm{SO}_{2}$ at an energy deposition of $60 \mathrm{~mJ} \mathrm{~cm}^{-3}$ is approximately the same in either pulse for-

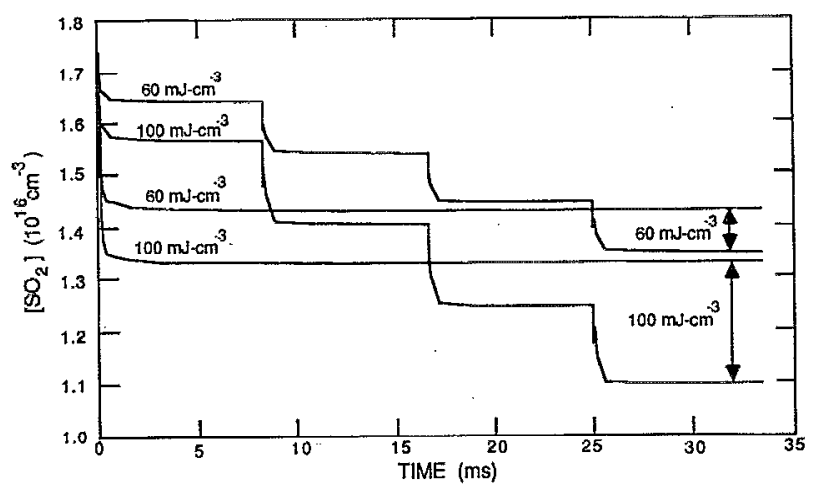

FIG. 9. Simulated $\mathrm{SO}_{2}$ concentration $\left(\left[\mathrm{SO}_{2}\right]_{0}=1000 \mathrm{ppmv}\right)$ for a total discharge energy deposition of 60 and $100 \mathrm{~mJ} \mathrm{~cm}^{-3}$. Energy is deposited in either a single pulse or four smaller pulses. The removal efficiency is larger when the energy/pulse is smaller due to a higher $E / N$ during the current pulse.

mat. At the higher-energy deposition, though, more total removal of $\mathrm{SO}_{2}$ is obtained by having energy deposition occur in a series of smaller pulses. The energy efficiency to remove $\mathrm{SO}_{2}$, though, behaves differently. As a measure of energy efficiency, let us define $\beta=\Delta\left[\mathrm{SO}_{2}\right] / E_{\text {Dep }}$ (change in $\left[\mathrm{SO}_{2}\right]$ /energy deposition). We find that $\beta$ increases as the energy/discharge pulse decreases, and $\beta$ increases as the number of pulses for a given energy deposition increases. For the results in Fig. $9, \beta=2.5$ ppmv/ $\left(\mathrm{mJ} \mathrm{cm}{ }^{-3}\right)$ for a single discharge pulse of $100 \mathrm{~mJ} \mathrm{~cm}^{-3}$ and $3.9 \mathrm{ppmv} /\left(\mathrm{mJ} \mathrm{cm}^{-3}\right)$ for a sequence of 4 pulses totalling $60 \mathrm{~mJ} \mathrm{~cm}^{-3}$.

The improvement in efficiency as the energy/pulse decreases is a consequence of the change in $E / N$ that occurs during the discharge pulse. Early during the current pulse, the $E / N$ is high and the rates of dissociation and excitation are also high. As the current pulse reaches a quasi-steadystate condition at a lower $E / N$, a larger fraction of the power is deposited into vibrational modes of the molecules, which does not directly produce precursors to $\mathrm{SO}_{2}$ removal. Therefore, many short current pulses which consist primarily of the avalanche stage produce a larger proportion of precursors by dissociation than does a single current pulse operating with a lower average $E / N$.

\section{COMBINED PLASMA PHOTOLYSIS}

Since chemical removal of $\mathrm{SO}_{2}$ is limited by generation of $\mathrm{OH}$ radicals, more efficient methods of producing $\mathrm{OH}$ should improve the efficiency of removing $\mathrm{SO}_{2}$ from gas streams. We suggest that uv illumination of the gas stream may serve this purpose. Large concentrations $\left(10^{14}-10^{15}\right.$ $\mathrm{cm}^{-3}$ ) of ozone $\left(\mathrm{O}_{3}\right)$ can be generated in DBDs. ${ }^{10} \mathrm{O}_{3}$ by itself, however, is relatively stable in these mixtures. $\mathrm{O}_{3}$ can, however, be photolyzed by uv light $(\lambda<300 \mathrm{~nm})$ producing $O\left({ }^{1} D\right)$ with a quantum yield of $>0.9 .{ }^{14}$ The $O\left({ }^{1} D\right)$ atoms then efficiently produce $\mathrm{OH}$ radicals by the reaction in Eq. (10). A similar strategy has been previously used in the removal of organics in liquid $\mathrm{H}_{2} \mathrm{O},{ }^{22,23}$ 
TABLE I. Photolysis reactions included in the model.

\begin{tabular}{lc}
\hline \hline Process & Cross section at $254 \mathrm{~nm}\left(\mathrm{~cm}^{2}\right)^{\mathrm{a}}$ \\
\hline $\mathrm{O}_{3}+h v \rightarrow \mathrm{O}\left({ }^{1} D\right)+\mathrm{O}_{2}$ & $1.5 \times 10^{-17}$ \\
$\mathrm{HO}_{2}+h v \rightarrow \mathrm{OH}+\mathrm{O}$ & $2.2 \times 10^{-19}$ \\
$\mathrm{H}_{2} \mathrm{O}_{2}+h v \rightarrow 2 \mathrm{OH}$ & $7.0 \times 10^{-20}$ \\
$\mathrm{NO}_{2}+h v \rightarrow \mathrm{NO}+\mathrm{O}$ & $1.7 \times 10^{-20}$ \\
$\mathrm{HNO}_{3}+h v \rightarrow \mathrm{OH}+\mathrm{NO}_{2}$ & $1.9 \times 10^{-20}$
\end{tabular}

${ }^{2}$ B. J. Finlayson-Pitts and J. N. Pitts, Jr., Atmospheric Chemistry: Fundamentals and Experimental Techniques (Wiley, New York, 1986), pp. 405-580, 1986; W. B. DeMore, M. J. Molina, S. P. Sander, D. M. Golden, R. F. Hampson, M. J. Kurylo, C. J. Howard, and A. R. Ravishankara, "Chemical Kinetics and Photochemical Data for use in Stratospheric Modeling: Evaluation Number 8," JPL Publication 87-41, Jet Propulsion Laboratory, California Institute of Technology, Pasadena, California, 1987.

To investigate the potential benefits of simultaneously using uv illumination and plasma to remove $\mathrm{SO}_{2}$ from gas streams, we included the photolysis reactions shown in Table I in our model. The results of combined plasma and optical processing are shown in Fig. 10 where $\left[\mathrm{SO}_{2}\right]$ and $\left[\mathrm{O}_{3}\right]$ densities during and after a single discharge pulse are shown with and without uv illumination at $\lambda=254 \mathrm{~nm}$. ${ }^{24}$ (Recall that a large fractional removal of $\mathrm{SO}_{2}$ results from a series of such pulses.) In the absence of uv illumination $\left[\mathrm{O}_{3}\right]$ decays fairly slowly, predominantly by reaction with $\mathrm{O}_{2}$. With photolysis, the $\left[\mathrm{O}_{3}\right]$ is rapidly depleted, producing $\mathrm{O}\left({ }^{1} D\right)$. the increased $\left[\mathrm{O}\left({ }^{1} D\right)\right]$ produces a higher $[\mathrm{OH}]$ by the reaction in Eq. (10). OH then quickly reacts with $\mathrm{SO}_{2}$ and $\mathrm{HSO}_{3}$ completing the removal of $\mathrm{SO}_{2}$. The chemical sequence is summarized by

$$
\begin{aligned}
e+\mathrm{N}_{2} & \rightarrow \mathrm{N}_{2}(A) \stackrel{\mathrm{O}_{2}}{\rightarrow} \stackrel{\mathrm{O}_{2}}{\rightarrow} \stackrel{h v}{\rightarrow} \stackrel{\mathrm{O}_{3} \rightarrow \mathrm{O}}{\rightarrow} \mathrm{O}\left({ }^{1} D\right) \stackrel{\mathrm{H}_{2}}{\rightarrow} \mathrm{OH} \rightarrow \mathrm{HSO}_{3} \\
& \mathrm{OH} \\
& \rightarrow \mathrm{H}_{2} \mathrm{SO}_{4} .
\end{aligned}
$$

Though $\mathrm{O}_{3}$ is fairly long lived, it does decrease in concentration as a result of collisions with $\mathrm{O}_{2}$ and $\mathrm{N}_{2}$. Therefore one must use a uv flux that is sufficiently high that $\mathrm{O}_{3}$ is photolyzed before removal from the gas phase by other mechanisms. When using $120 \mathrm{~Hz}$ in a DBD, one should ideally utilize the $\mathrm{O}_{3}$ in the interpulse period as $\mathrm{O}_{3}$ can be consumed during the following pulse. This latter constraint can be somewhat relaxed under actual operating conditions since every gas volume is not processed by the DBD on every half-cycle. The minimum uv flux required to fully utilize $\mathrm{O}_{3}$ can be estimated by

$$
\Phi \sigma>\sum_{i} k_{i} N_{i}
$$

where $\Phi$ is the uv flux (photons $/ \mathrm{cm}^{2}$ ), $\sigma$ is the photolysis cross section $\left(1.15 \times 10^{-17} \mathrm{~cm}^{2}\right)$, and $k_{i}$ is the rate coefficient for species $i$ having concentration $N_{i}$ to react with $\mathrm{O}_{3}$. The dominant quenching species during and after a current pulse and their rate coefficients at room tempcrature are shown in Table II. Using species concentrations during and following a typical current pulse, one finds that high utilization of generated $\mathrm{O}_{3}$ is obtained when $\Phi$ $>10-20 \mathrm{~W} \mathrm{~cm}^{-2}$. [ $\left[\mathrm{SO}_{2}\right]$ during and after a single dis-

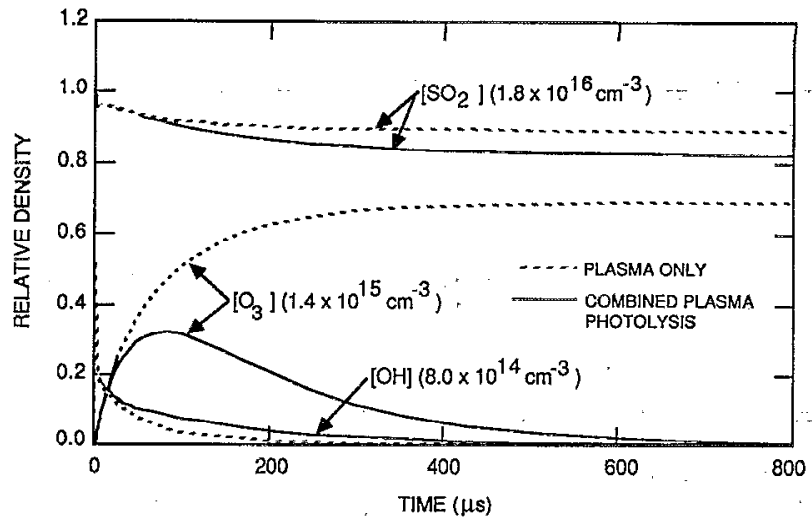

FIG. 10. $\left[\mathrm{SO}_{2}\right],\left[\mathrm{O}_{3}\right]$, and $[\mathrm{OH}]$ immediately after a current pulse (duration $<1 \mu \mathrm{s}$ ) showing conditions with and without uv illumination. The indicated numerical values are the respective maximum densities. The photolysis depletes $\mathrm{O}_{3}$, generating $\mathrm{O}\left({ }^{1} D\right)$ atoms, which in turn increase the $\mathrm{OH}$ density by $\mathrm{H}$ abstraction from $\mathrm{H}_{2} \mathrm{O}$. Improved removal of $\mathrm{SO}_{2}$ results.

charge pulse as computed with the model is shown in Fig. 11 for different uv fluxes. The minimum uv flux required for high utilization of $\mathrm{O}_{3}$ during a single interpulse period is $10-20 \mathrm{~W} \mathrm{~cm}^{-2}$, confirming our estimate based on quenching. Allowing that each gas volume is not processed on each half-cycle, this minimum flux may be lowered somewhat. However its value will ultimately be limited by kinetic quenching of $\mathrm{O}_{3}$ to many $\mathrm{W} \mathrm{cm}{ }^{-2}$. At high levels of illumination, the removal of $\mathrm{SO}_{2}$ may actually decrease slightly due to the photolysis of intermediates in the chemical removal process, principally $\mathrm{HO}_{2}$.

The absorbed optical energy required to photolyze $\mathrm{O}_{3}$ is very nearly one photon per molecule since absorption cross sections for other components in the gas stream at $250 \mathrm{~nm}<\lambda<300 \mathrm{~nm}$ are small. For $\mathrm{O}_{3}$ concentrations of $10^{14}-10^{15} \mathrm{~cm}^{-3}$ and $\lambda=254 \mathrm{~nm}$, total photolysis of $\mathrm{O}_{3}$ occurs with an absorbed optical energy of $0.1-1 \mathrm{~mJ} \mathrm{~cm}^{-3}$. Incoherent sources of uv radiation in the desired wavelength range have intrinsic energy efficiencies as high as $30 \% .{ }^{10}$ The energy required per discharge pulse to completely photolyze $\mathrm{O}_{3}$ is therefore $0.3-3 \mathrm{~mJ} \mathrm{~cm}^{-3}$.

The practicality of plasma-based removal of $\mathrm{SO}_{2}$ from gas streams depends in large part on matters such as the energy budget, and the presence of other impurities in the gas stream. For example, $\mathrm{CO}_{2}$ is a product of combustion and is contained in flue gases to about $10 \%$ by volume. The presence of other gases usually decreases the efficiency of removal of $\mathrm{SO}_{2}$ by intercepting intermediate radicals. $\mathrm{CO}_{2}$ quenches $\mathrm{O}\left({ }^{1} D\right)\left(k=7.4 \times 10^{-11} \mathrm{~cm}^{3} \mathrm{~s}^{-1}\right)$ and therefore will reduce the production of $\mathrm{OH}$ by hydrogen abstraction from $\mathrm{H}_{2} \mathrm{O}$. The presence of $\mathrm{NO}_{x}$ in flue gases reduces the removal of $\mathrm{SO}_{2}$, however the same chemistry contributes to the removal of $\mathrm{NO}_{x}$ via oxidation by $\mathrm{OH}$ to $\mathrm{HNO}_{3}$. This aspect of removal in DBDs will be addressed in an upcoming publication.

The energy deposition required for total removal of $\mathrm{SO}_{2}$ (1000 ppmv) in a $\mathrm{N}_{2} / \mathrm{O}_{2} / \mathrm{H}_{2} \mathrm{O}=0.7 / 0.2 / 0.1$ mixture is shown in Fig. 12. Results are shown for using plasma 
TABLE II. Gas species reacting with $\mathrm{O}_{3}$ generating products other than $O\left({ }^{1} D\right)$.

\begin{tabular}{lcc}
\hline Species & Rate coefficient $\left(\mathrm{cm}^{3} \mathrm{~s}^{-1}\right)$ & Reference \\
\hline $\mathrm{O}$ & $8.3 \times 10^{-15}$ & $\mathrm{a}$ \\
$\mathrm{N}$ & $5.0 \times 10^{-17}$ & $\mathrm{~b}$ \\
$\mathrm{OH}$ & $6.8 \times 10^{-14}$ & $\mathrm{c}$ \\
$\mathrm{SO}$ & $9.1 \times 10^{-14}$ & $\mathrm{c}$ \\
$\mathrm{NO}$ & $4.6 \times 10^{-14}$ & $\mathrm{~b}$ \\
$\mathrm{NO}_{2}$ & $3.4 \times 10^{-17}$ & $\mathrm{~b}$ \\
$\mathrm{HO}_{2}$ & $1.9 \times 10^{-15}$ & $\mathrm{c}$ \\
\hline \hline
\end{tabular}

${ }^{a}$ R. Atkinson, D. L. Baulch, R. A. Cox, R. F. Hampson, J. A. Kerr, and J. Troe, Int. J. Chem. Kinet. 21, 115 (1989).

bJ. C. Pearson and D. O. Ham, Radiat. Phys. Chem. 31, 1 (1988).

'S. Mukkavilli, C. K. Lee, K. Varghese, and L. L. Tavlarides, IEEE Trans. Plasma Sci. 16, 652 (1988).

excitation only, and with combined plasma photolysis. The parametrization is over discharge pulse energy deposited in the gas, and shows that more efficient removal occurs with smaller energy/pulse. DBDs deposit small amounts of energy/pulse, and are at the left of the figure. The results also show that large amounts of energy are required to remove $\mathrm{SO}_{2}$ when using only the plasma in the large-pulse regime. Processing using combined plasma photolysis requires about half the discharge energy for the same removal. To estimate the total amount of energy (directly deposited in the plasma and energy expended in generating the uv photons), we assumed that the uv flux could be produced with an energy efficiency of $30 \%$, and that half of the uv flux is absorbed in the plasma. The former efficiency has been demonstrated in incoherent uv sources using excimer molecules. ${ }^{11}$ With these assumptions, the total energy required for removal is also shown in Fig. 12 and can be less than $100 \mathrm{~mJ} \mathrm{~cm}^{-3}$. In $e$-beam-based plasma processing $\gtrsim 100 \mathrm{~mJ} \mathrm{~cm}^{-3}$ are required to remove $1000 \mathrm{ppmv}$ of $\mathrm{SO}_{2} \cdot{ }^{19}$ Therefore combined plasma photolysis using DBDs appears to be quite competitive with $e$-beam-based removal techniques.

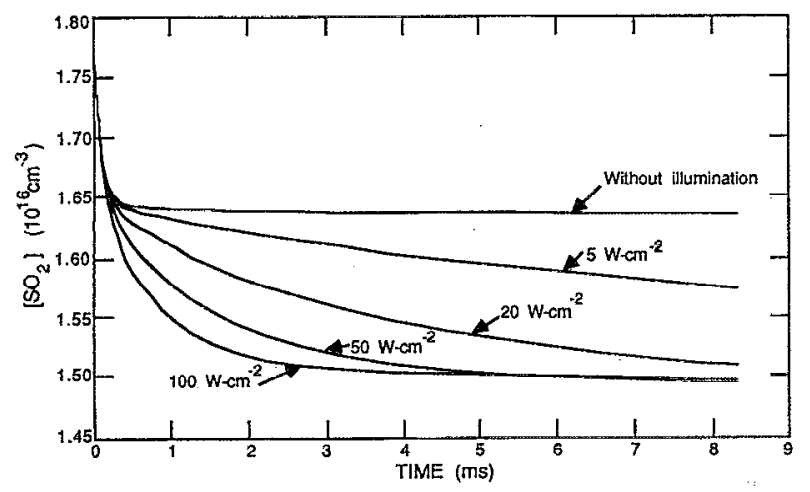

FIG. 11. $\mathrm{SO}_{2}$ removal for various uv illumination levels. A minimum illumination is required to fully utilize $\mathrm{O}_{3}$ before it is otherwise quenched.

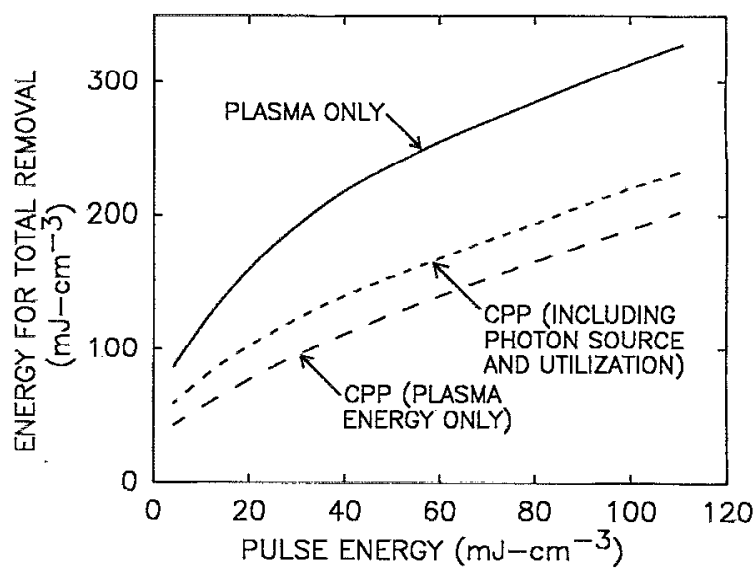

FIG. 12. Discharge energy required to totally remove $\mathrm{SO}_{2}$ as a function of energy deposition/pulse using many such pulses. Results are shown with and without photolysis. The total energy required including the generation and transport of the uv flux was obtained assuming a net photon efficiency of $15 \%$

\section{CONCLUDING REMARKS}

In conclusion, we have experimentally and theoretically demonstrated the removal of $\mathrm{SO}_{2}$ in gas streams containing $\mathrm{H}_{2} \mathrm{O}$ using dielectric barrier discharges. Removal increases under conditions where the production of the $\mathrm{OH}$ radical is enhanced; increasing $\left[\mathrm{O}_{2}\right]$ and $\left[\mathrm{H}_{2} \mathrm{O}\right]$ achieves these goals. Further improvements in removal of $\mathrm{SO}_{2}$ can be obtained by illuminating the plasma with uv light to photolyze $\mathrm{O}_{3}$. The resulting $\mathrm{O}\left({ }^{1} D\right)$ atoms abstract $\mathrm{H}$ from $\mathrm{H}_{2} \mathrm{O}$, thereby increasing the production of $\mathrm{OH}$, and improving removal of $\mathrm{SO}_{2}$ from the gas stream. Improvements of $100 \%$ in the rate of removal of $\mathrm{SO}_{2}$ can be obtained using this method. Excitation schemes which have many short-current pulses with high average $E / N$ results in more efficient removal than a smaller number of longcurrent pulses. Dielectric barrier discharges are ideal in this regard. From an energy budgeting viewpoint, only short-pulse excitation schemes are likely to be efficient enough to be considered for commercial applications.

\section{ACKNOWLEDGMENTS}

This work was supported through the Advanced Environmental Control Technology Center under contract to the United States Environmental Protection Agency (EPA Cooperative Agreement CR812582) and the National Science Foundation (ECS88-15781 and CBT88-03170). Although the research reported in this article has been funded in part by the United States Environmental Protection Agency, it has not been subjected to the Agency's required peer and administrative review. It therefore does not necessarily reflect the views of the Agency and no official endorsement should be inferred.

\footnotetext{
${ }^{1}$ J. D. Spengler, M. Brauer, and P. Koutrakis, Environ. Sci. Technol. 24, 946 (1990).

${ }^{2}$ P. J. Temple, J. Air Pollut. Control Assoc. 22, 271 (1972).
} 
${ }^{3}$ K. L. Gauri and G. C. Holdren, Jr., Environ. Sci. Technol. 15, 386 (1981).

${ }^{4} \mathrm{G}$. E. Gordon, in The Chemistry of Acid Rain, Sources and Atmospheric Processes, edited by R. W. Johnson and G. E. Gordon (American Chemistry Society, 1987), p. 3.

${ }^{5} \mathrm{~J}$. Meyler, Combustion 52, 21 (1981).

${ }^{\circ}$ K. Kawamura and V. H. Sui, Radiat. Phys. Chem. 24, 117. (1984).

${ }^{7}$ S. Masuda, Pure Appl. Chem. 60, 727 (1988).

${ }^{8}$ I. Gallinberti, Pure Appl. Chem. 60, 663 (1988)

${ }^{9}$ I. Sardja and S. K. Dhali, Appl. Phys. Lett. 56, 21 (1990).

${ }^{10}$ B. Eliasson, M. Hirth, and U. Kogelschaiz, J. Phys. D 20, 1421 (1987).

"B. Eliasson and U. Kogelschatz, Appl. Phys. B 46, 299 (1988).

${ }^{12} \mathrm{O}$. Tokunga and N. Suzuki, Radiat. Phys. Chem. 24, 145 (1985).

${ }^{13}$ W. Licht, Air Pollution Control Engineering: Basic Calculations for Particulate Collection, 2nd ed. (Marcel Dekker, New York, 1988).

${ }^{14}$ W. B. DeMore, "Chemical Kinetics and Photochemical Data for Use in Stratospheric Modeling. Evaluation Number 7," NASA-JPL Publications $85-37$, July 1985 .

${ }^{15}$ Mention of trade names or commercial products does not imply endorsement or recommendation for use by the sponsors of this work.
${ }^{16}$ M. Kushner, A. Pindroh, C. H. Fisher, T. A. Znotins, and J. J. Ewing, J. Appl. Phys. 57, 2486 (1985).

${ }^{17}$ W. L. Morgan and B. M. Penetrante, Comp. Phys. Commun. 58, 127 (1990).

${ }^{18}$ F. Busi, M. D'Angelantonio, Q. G. Mulazzani, V. Raffaelli, and $O$. Tubertini, Radiat. Phys. Chem. 25, 47 (1985).

${ }^{19}$ J. C. Pearson and D. O. Ham, Radiat. Phys. Chem. 31, 1 (1988).

${ }^{20} \mathrm{~A}$ complete listing of species, reactions, and rate coefficients may be obtained by contacting the authors (M.J.K.).

${ }^{21}$ B. Eliasson and U. Kogelschatz, IEEE Trans. Plasma Sci. (to be published).

${ }^{22}$ G. R. Peyton and W. H. Glaze, Environ. Sci. Technol. 22, 761 (1988).

${ }^{23}$ J. Drimal and J. Janca, J. Phys. D 23, 7 (1990).

${ }^{24}$ The choice of $\lambda=254 \mathrm{~nm}$ ( $\mathrm{Hg}$ resonance line) is based on the availability of high uv fluxes from high-pressure arc lamps. The technology of these lamps is fairly mature, having been developed for disinfectants, and is commercially available. Other sources of incoherent uv light from excimer molecules are also available at a higher intrinsic efficiency. See Ref. 11. 